\title{
QT Interval Shortening After Bariatric Surgery: Mind the Heart Rate Correction Equation
}

\author{
Bernd Schultes $^{1}$ (D) $\cdot$ Erik Konrad Grasser ${ }^{2} \cdot$ Barbara Ernst $^{1}$ \\ Received: 21 April 2021 / Revised: 21 April 2021 / Accepted: 25 April 2021 / Published online: 3 June 2021 \\ (C) The Author(s), under exclusive licence to Springer Science+Business Media, LLC, part of Springer Nature 2021
}

We thank Sanches et al. for their systematic review and metaanalysis on the effects of bariatric surgery on obesityassociated electrocardiogram (ECG) abnormalities and cardiac arrhythmias [1]. Based on their meta-analysis of seven studies, the authors report on a heart rate-corrected QT (QTc) interval length shortening of $-33.6 \mathrm{~ms}, 95 \% \mathrm{CI}$ [49.8 to $-17.4 \mathrm{~ms}$ ] after bariatric surgery. We would like to bring the author's attention to a methodological issue that in our view should not be neglected, i.e., the equation used for the QT interval length correction for heart rate.

We have previously reported on electrocardiography (ECG) recordings analysis of 49 (35 females) patients with severe obesity before and 12 months after Roux-en-Y gastric bypass (RYGB) surgery [2]. Similar to Sanches et al. we found a QTc interval length reduction of (mean \pm standard deviation) $-31 \pm 18 \mathrm{~ms}$ when we used the most frequently applied Bazett equation for heart rate correction. However, when we used the correction equations by Fridericia, Framingham, and Hodges, the reduction of the QTc interval length was markedly smaller (i.e., $-12 \pm 15 \mathrm{~ms} ;-14 \pm 15 \mathrm{~ms}$; $-9 \pm 15 \mathrm{~ms}$, respectively, all $\mathrm{p}<0.001$ vs. QTc interval reduction by Bazett). Furthermore, we found that postoperative changes in QTc interval length were correlated with changes in heart rate when data were calculated upon the Bazett equation $(r=0.57, p<0.005)$ but not when calculated upon the other equations. This suggests that the Bazett

Bernd Schultes

bernd.schultes@friendlydocs.ch

1 Metabolic Center St. Gallen, friendlyDocs Ltd., Lerchentalstreet 21, CH-9016 St. Gallen, Switzerland

2 Steiermärkische Krankenanstaltengesellschaft m.b.H, LKH Hochsteiermark, Styria, Austria equation is very sensitive to heart rate changes which is important since weight loss is frequently accompanied by a reduction of resting heart rate. Based on our findings, we concluded that the extent of weight loss-associated QTc interval shortening largely depends on the applied heart rate correction equation and appears to be overestimated when the most popular Bazett's equation is used.

Unfortunately, Sanches et al. [1] do not provide exact information on the correction equations but only state that "... Bazett's formula is often used in the included studies....". If so, the reported QTc interval length reduction could be likewise overestimated. While overall we believe that the author's conclusion on a reduction of the QT interval length is valid, we think that the potentially biasing influence of using the Bazett equation should be acknowledged as it might have an influence on the pathophysiological and clinical significance of the finding.

\section{Declarations}

Ethical Approval Not applicable to this type of study (letter to the editor).

Conflict of Interest The authors declare no competing interests.

\section{References}

1. Sanches EE, Topal B, de Jongh FW, et al. Effects of bariatric surgery on heart rhythm disorders: a systematic review and meta-analysis. Obes Surg. 2021;31(5):2278-90.

2. Grasser EK, Ernst B, Thurnheer M, et al. QT interval shortening after bariatric surgery depends on the applied heart rate correction equation. Obes Surg. 2017;27(4):973-82.

Publisher's Note Springer Nature remains neutral with regard to jurisdictional claims in published maps and institutional affiliations. 